\title{
Is retirement good or bad for mental and physical health functioning? Whitehall II longitudinal study of civil servants
}

\author{
G Mein, P Martikainen, H Hemingway, S Stansfeld, M Marmot
}

See end of article for

authors' affiliations

J Epidemiol Community Health 2003;57:46-49

.....................

Correspondence to: $G$ Mein, International Centre for Health and Society, Department of Epidemiology and Public Health, Royal Free and University College Medical School, 1-19 Torrington Place, London WC1E 6BT, UK; g.mein@

public-health.ucl.ac.uk

Accepted for publication 19 March 2002

\begin{abstract}
Background: To determine whether retirement at age 60 is associated with improvement or deterioration in mental and physical health, when analysed by occupational grade and gender.

Methods: Longitudinal study of civil servants aged 54 to 59 years at baseline, comparing changes in SF-36 health functioning in retired $(n=392)$ and working $(n=618)$ participants at follow up. Data were collected from self completed questionnaires.

Results: Mental health functioning deteriorated among those who continued to work, but improved among the retired. However, improvements in mental health were restricted to those in higher employment grades. Physical functioning declined in both working and retired civil servants.

Conclusion: The study found that retirement at age 60 had no effects on physical health functioning and, if anything, was associated with an improvement in mental health, particularly among high socioeconomic status groups.
\end{abstract}

T he age at which people retire is decreasing and this, coupled with the increase in life expectancy, has expanded the length of time people spend in retirement. ${ }^{1}$ Currently, those retiring at the age of 60 may anticipate about two decades in retirement. ${ }^{2}$ This has implications for those retiring and those who provide services for the retired. Previous studies that have investigated the effect of retirement on mental and physical health give conflicting results; with studies finding adverse, ${ }^{45}$ no, ${ }^{6-8}$ or even beneficial ${ }^{9}$ health effects. The reasons for these discrepant findings lie, in part, in the methodological limitations of retrospective study designs, ${ }^{10}$ and in analyses of data that are unable to separate the effects of aging and retirement. ${ }^{11}$ Furthermore, they lack adequate comparison groups, validated measurements of mental and physical health, within person repeated measures of changes in health, and consideration of the effects of socioeconomic status and baseline health. In addition the experience of beneficial or adverse changes in life circumstances at retirement are likely to vary depending upon work characteristics before retirement as well as socioeconomic and marital status. Previous studies have not investigated the impact of retirement on change in both mental and physical health using validated scales.

In the Whitehall II study we sought therefore to overcome these limitations and determine the effects of normal retirement on change in physical and mental health functioning, using the 36-item short form health survey, which we have shown to be a valid measure of change in health. ${ }^{12}$ We compare the change in health among civil servants aged 54-59 at baseline who either retire normally (at the usual mandatory age of 60) or who are still working as civil servants at the time of follow up three years later. The Whitehall II study offers the advantages of a group of both men and women with comparatively precise definitions of social status and stable and homogenous employment before retirement.

\section{METHODS}

\section{Study population}

The Whitehall II study ${ }^{13}$ is a prospective study of men and women aged 35-55 years at the time of recruitment in 1985, working in 20 London based civil service departments. The study originally recruited 10308 men and women who completed a self administered health questionnaire and attended screening examination in 1985-1988 (phase 1). In 1989 a further postal questionnaire was carried out (phase 2), phase 3 (1991-93) included a screening examination and a postal questionnaire, phase 4 was a postal questionnaire in 1995. In this analysis phase 3 will be referred to as the baseline measurement and phase 4 as the follow up. The mean interval between baseline and follow up was 36 months (range 23-59 months). The response rate was $81 \%$ at phase three and $77 \%$ at phase four.

The civil service operates a mandatory retirement age of 60 years for both men and women, however in exceptional cases employees are permitted to work past this time.

Analyses were restricted to working civil servants aged 54-59 at baseline. At follow up these participants were categorised as ( 1 ) still working as civil servants $(n=618$, of which 239 were aged over 60), (2) retired at the mandatory retirement age in the civil service of 60 years $(n=392)$. We excluded 191 participants who described their departure from the civil service as ill health retirement, voluntary compulsory redundancy, or employment elsewhere.

\section{Measures}

Socioeconomic status and psychosocial work characteristics

Civil service employment grade title obtained at baseline was used as a measure of socioeconomic status. Three grades were defined that differ considerably in salaries. In 1995 the annual salary in the low grades was $£ 4000$ to $£ 10999$, for the medium grades was $£ 5500$ to $£ 26000$, and $£ 28975$ to $£ 150000$ for the high grades. Marital status was classified as married/ cohabiting compared with not.

Job control or job decision latitude, a measure combining work decision authority and skill discretion, is based on the Karasek job content instrument. ${ }^{14}{ }^{15}$ We also used an indicator of overall job satisfaction based on the question "All things 


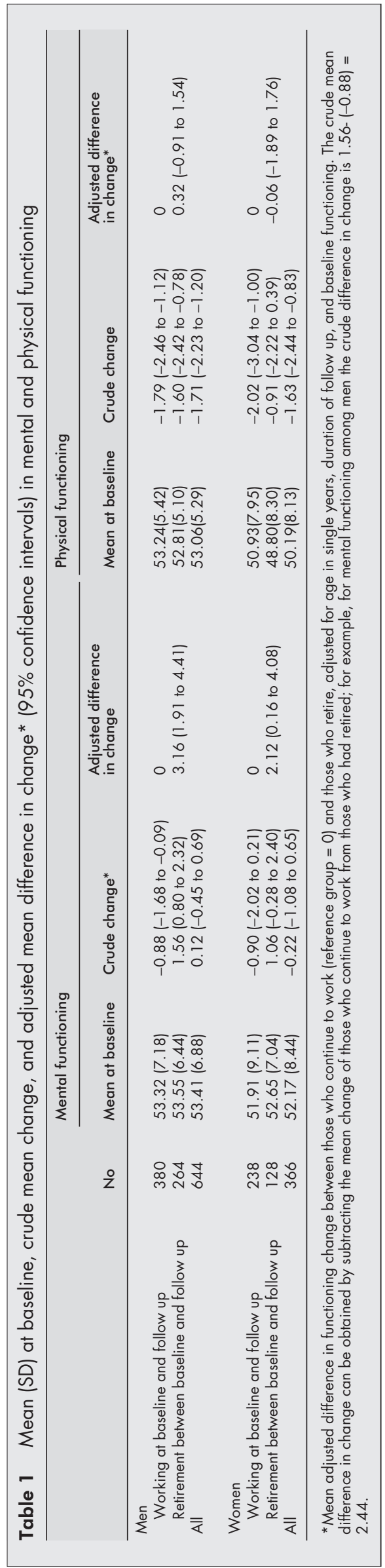

considered, how satisfied or dissatisfied are you with your job" dichotomised as satisfied or very satisfied compared with not.

\section{Health measures}

Mental and physical health were measured using scores of the SF-36 (The Short Form 36 General Health Survey) ${ }^{16}$ at baseline and follow up, on average 36 months apart. The SF-36 is a 36 item questionnaire which covers eight dimensions: physical functioning, role limitations attributable to physical problems, social functioning, bodily pain, general mental health, role limitations attributable to emotional problems, vitality, and general health perceptions. Based on factor analysis, these scores can be summarised into mental and physical summary components. ${ }^{17}{ }^{18}$ Low component summary scores imply low functioning and a mean of 50 is observed in the general US population. ${ }^{17} 18$

\section{Statistical analysis}

The results of linear regression models were presented in terms of the adjusted difference in change. The difference in change in the component summary score of those who had retired was compared with those who continued to work at follow up, adjusted for age in single years, length of follow up, and baseline summary component score.

We included participants who continued to work after the retirement age of 60 years in the reference group of working participants. As a consequence those who remained at work were only slightly younger than those who retired at follow up (for men the mean ages were $55.6 v 57.9$ years; for women 56.1 $v 57.9$ years). However, excluding participants who continued to work beyond age 60 did not change our conclusions.

\section{RESULTS}

Among men and women, differences in baseline functioning between those who continued to work and those who had retired at follow up were small (table 1). Mental functioning declined among those who continued to work and improved among those who had retired. The adjusted difference in change in mental functioning between working and retired participants was 3.16 points (95\% CI 1.91 to 4.41 ) among men, and 2.12 points (95\% CI 0.16 to 4.08 ) among women. Physical functioning declined during follow up among men and women, and there were no significant differences between working and retired participants. Adjustment for baseline functioning had little effect on the estimated difference in change in physical and mental functioning.

To assess whether changes in physical and mental functioning among working and normally retired participants varied by employment grade, marital status, job satisfaction, or job control, we carried out further analyses combining men and women and adjusting for sex and age in single years. Tests for interactions at the 5\% significance level indicated that change in physical functioning among working and normally retired participants did not differ by employment grade, marital status, job satisfaction, or job control.

However, changes in mental functioning between working and normally retired participants varied by grade (table 2 ). Improvements in mental health functioning among normal retirees were observed only among the two highest civil service grades. Adjusting for marital status, job satisfaction, job control, as well as the physical component summary score did not change this association.

\section{DISCUSSION}

In a longitudinal study of civil servants all initially working, those retiring at the mandatory age of 60, compared with those remaining in work, reported no adverse effects on physical health functioning. This is consistent with an age related process of physical functioning decline. By examining a widely used continuous measure of physical health 
Table 2 Crude mean change and adjusted mean difference in change* (95\% confidence intervals) in mental and physical functioning by civil service employment grade

\begin{tabular}{|c|c|c|c|}
\hline & Grade I (high) & Grade II (medium) & Grade III (low) \\
\hline \multicolumn{4}{|l|}{ Mental functioning } \\
\hline \multicolumn{4}{|l|}{ Crude change } \\
\hline Working at baseline and follow up & $-1.09(-2.17$ to 0.00$)$ & $-0.43(-1.57$ to 0.71$)$ & $-1.26(-2.39$ to -0.12$)$ \\
\hline Retirement between baseline and follow up & 2.10 (1.23 to 2.97$)$ & $1.52(0.42$ to 2.62$)$ & $-0.85(-2.92$ to 1.21$)$ \\
\hline \multicolumn{4}{|l|}{ Adjusted difference in change ${ }^{*}$} \\
\hline Working at baseline and follow up & 0 & $0.42(-0.99$ to 1.83$)$ & $-0.13(-1.71$ to 1.45$)$ \\
\hline Retirement between baseline and follow up & $3.53(1.88$ to 5.18$)$ & $3.04(1.38$ to 4.70$)$ & $0.59(-1.74$ to 2.93$)$ \\
\hline \multicolumn{4}{|l|}{ Physical functioning } \\
\hline \multicolumn{4}{|l|}{ Crude change } \\
\hline Working at baseline and follow up & $-0.86(-1.72$ to -0.01$)$ & $-1.95(-2.93$ to -0.98$)$ & -2.77 (-3.85 to -1.69$)$ \\
\hline Retirement between baseline and follow up & $-1.89(-2.95$ to -0.84$)$ & $-0.74(-1.80$ to 0.31$)$ & $-1.78(-3.77$ to 0.22$)$ \\
\hline \multicolumn{4}{|l|}{ Adjusted difference in change* } \\
\hline Working at baseline and follow up & 0 & $-1.60(-2.95$ to -0.24$)$ & $-2.86(-4.38$ to -1.34$)$ \\
\hline Retirement between baseline and follow up & $-1.54(-3.12$ to 0.05$)$ & $-1.06(-2.65$ to 0.54$)$ & $-2.75(-4.98$ to -0.51$)$ \\
\hline Number & 351 & 404 & 254 \\
\hline \multicolumn{4}{|c|}{$\begin{array}{l}\text { *Adjusted mean difference in change in functioning (reference group is employed grade I civil servants who worked at baseline and at follow up }=0 \text { ), } \\
\text { adjusting for age in single years, sex, duration of follow up, and baseline functioning. One participant was excluded because of missing information o } \\
\text { grade. Men and women are combined for these analysis, as the pattern of results by sex is very similar. }\end{array}$} \\
\hline
\end{tabular}

functioning, these findings extend those of the few previous prospective studies. ${ }^{679}$ The results further show that mental health functioning improved among those retiring. However, improvement in mental health after retirement was restricted to those in high employment grades. The grade difference in change in mental health functioning may be understood as the benefits of giving up work and the rewards of retiring. Improvement in mental health after normal retirement in high grade civil servants may be attributable to the benefits of the removal of work demands and work induced stress. Indeed, our analysis covered a period that included substantial reorganisation in the civil service, the avoidance of which may have given people an added benefit when retiring. In addition high grade civil servants receive a higher pension than their colleagues in lower grades and therefore have more choice in the type of lifestyle they can enjoy. Lower grade civil servants may also benefit from giving up work but these may be outweighed by the relative material disadvantage of retirement. This is supported by results from qualitative interviews showing that lower grade civil servants do indeed worry about their reduced income in retirement. ${ }^{19}$ Our finding of improvement in the mental health of high grade civil servants is consistent with a smaller study of workers in Finland.

There were no differences in physical health functioning deterioration in those who continued to work and those who had retired at normal age; this is consistent with an age related process of physical functioning decline. By examining a widely used continuous measure of physical health functioning, these findings extend those of the few previous prospective studies. Based on clinical examinations of men retiring over a wide age range (55-73 years) Ekerdt et al found no effect of retirement on physical health. ${ }^{6}$ Salokangas found no effect of retirement on the number of self reported physical illnesses. ${ }^{7}$ Furthermore, Tuomi $e t$ al ${ }^{9}$ found mixed effects of retirement on muscoloskeletal diseases, cardiovascular diseases, and mental diseases, and that these effects depended upon the type of work before retirement.

The British civil service employs a large number of administrators and general office staff and this makes it equivalent to many office work based work settings. In examining the effects of retirement on health it is impossible to select a strictly age comparable reference group in the setting (widespread in Europe) of a mandatory retirement age. To avoid this problem, we selected a narrow (six year) age band and also included those participants who continued to work in the civil service after age 60 . This resulted in retirees being

\section{Key points}

- It is often assumed that retirement adversely affects health, although scientific studies have found conflicting evidence for this.

- We studied changes in mental and physical health functioning in London based civil servants aged 54 to 59 years.

- Mental health functioning improves after retirement but only in high employment grades.

- Change in physical health functioning is not associated with retirement.

- We conclude that normal retirement is not associated with adverse changes in health.

only slightly (about two years) older than those who continue to work. The effects of this age difference are unlikely to confound our main conclusion that retirement itself has no adverse health consequences. We adjusted for age (in single years) and found similar results when comparing voluntary early retirees with those still working, two groups identical in age (results not shown here).

We conclude that retirement is not associated with decline in health in the short-term; using a widely validated measure of health functioning (SF-36) no adverse changes were seen among a group of office based workers retiring in the mid 1990s.

\section{ACKNOWLEDGEMENTS}

We thank all participating civil service departments and their welfare, personnel, and establishment officers; the Occupational Health and Safety Agency; the Council of Civil Service Unions; all participating civil servants in the Whitehall II study; and all members of the Whitehall II study team.

\section{Contributors}

The first draft was written by GM. The analysis was done by PM. PM, $\mathrm{HH}$, SS and MM critically reviewed all drafts of the paper.

Authors' affiliations

G Mein, P Martikainen, H Hemingway, M Marmot, International Centre for Health and Society, Department of Epidemiology and Public Health, Royal Free and University College Medical School, London, UK P Martikainen, Population Research Unit, Department of Sociology, University of Helsinki, Finland 
H Hemingway, Department of Research and Development, Kensington \& Chelsea and Westminster Health Authority, London, UK

Funding: The Whitehall II study has been supported by grants from the Medical Research Council, British Heart Foundation, Health and Safety Executive, National Heart Lung and Blood Institute (HL363 10), National Institute on Aging (AG13196), Agency for Health Care Policy Research (HSO6516), The New England Medical Centre: Division of Health

Improvement, Institute for Work and Health, Toronto, and the John D and

Catherine T MacArthur Foundation Research Networks on Successful Midlife Development and Socio-economic Status and Health. PM is supported by the Academy of Finland (grant 48600 and 53234) and the Signe and Ane Gyllenberg Foundation. MM is supported by an MRC Research Fellowship. HH is supported by a Public Health Career Scientist Award from the Department of Health, UK.

Conflicts of interest: none.

\section{REFERENCES}

1 Gruber J, Wise D. Introduction and summary. In: Social security and retirement around the world. National Bureau of Economic Research. Chicago. The University of Chicago Press. 1999:35.

2 Central Statistical Office. Social trends 26. London: HMSO, 1996:130.

3 Hedstrom P, S Ringen. Age and income in contemporary society: a research note. Journal of Social Policy 1987;16:227-39.

4 Casscells W, Evans D, De Silva RA, et al. Retirement and coronary mortality. Lancet 1980;i:1288-9.

5 Bosse R, Aldwin CM, Levenson MR, et al. Mental health differences among retirees and workers: findings from the Normative Aging Study. Psychol Aging 1987;2:383-9.

6 Ekerdt D, Baden L, Bosse R, et al. The effect of retirement on physical health. Am J Public Health 1983;73:779-83.
7 Salokangas RK, Joukamaa M. Physical and mental health changes in retirement age. Psychotherapy Psychosom 1991;55:100-7

8 Midanik LT, Soghikian K, Ransom L, et al. The effect of retirement on mental health and health behaviors: The Kaiser Permanente Retirement Study. J Gerontol Social Sci 1995;50B:s59-61.

9 Tuomi K, Järvinen E, Eskelinen L, et al. Effect of retirement on health and work ability among municipal employees. Scand J Work Environ Health $1991 ; 17$ (suppl 1):75-81.

10 Kremer $Y$. The association between health and retirement: self-assessment of Israeli retirees. Soc Sci Med 1985;20:1:61-6.

11 Ostberg H, Samuelsson SM. Occupational retirement in women due to age. Health aspects. Scand J Soc Med 1994; 22:90-6.

12 Hemingway $\mathbf{H}$, Stafford M, Stansfeld S, et al. Is the SF-36 a valid measure of change in population health? Results from the Whitehall study. BM 1997;315:1273-8.

13 Marmot MG, Davey Smith G, Stansfeld SA, et al. Health inequalities among British civil servants: the Whitehall II study. Lancet 1991;337: 1387-93.

14 Karasek R, Theorell T. Healthy work: stress, productivity, and the reconstruction of working life. New York: Basic Books, 1990.

15 Bosma H, Marmot MG, Hemingway H, et al. Low job control and risk of coronary heart disease in the Whitehall II (prospective cohort) study. BM 1997:314:558-65.

16 Ware JE, Snow KK, Kosinski M, et al. SF-36 Health survey manual and interpretation guide. Boston: New England Medical Center, 1993.

17 Ware JE, Kosinski M, Keller SD. SF-36 Physical and mental summary scales: a user's manual. Boston, MA: The Health Institute, 1994.

18 Ware JE, Kosinski M, Bayliss MS, et al. Comparison of methods for the scoring and statistical analysis of SF-36 health profile and summary measures: summary of results from the medical outcomes study. Med Care1995;33:AS264-79.

19 Mein G, Higgs P, Ferrie J, et al. Paradigms of retirement: the importance of health in ageing in the Whitehall II study. Soc Sci Med 1998;47:535-45. 